\title{
Perfect Pregnancy? Pregnant Bodies, Digital Leisure and the Presentation of Self
}

\begin{abstract}
Pregnant women are increasingly engaging with social media as a form of digital leisure. In doing so, they subject themselves to normalised images of pregnant bodies communicating unrealistic ideals. Instagram is a culturally communicative and visual platform and a pervasive context in which to explore body discipline and regulation. The current research utilised discourse analysis to explore dominant discourse surrounding pregnant women's bodies through their self-presentation on Instagram, uncovering potential areas of challenge and resistance. Content was selected from 60 user-generated posts from 16 pregnant women's personal accounts on Instagram. Results explore themes of 'The 'Perfect Pregnancy and Middle-class, Consumptive Ethic', 'Doing Exclusive Heteronormative Pregnant Femininity' and 'Self-surveillance \& Hyper-visibility of the Digital Fleshy Pregnant Body'. These themes identified how pregnant women embody dominant discourse regarding neoliberalism, consumption, traditional medicine, heteronormativity, and hegemonic masculinity, and use this to engage in self-surveillance, policing, and monitoring of their pregnant bodies. A final theme Rejecting the 'Perfect Pregnancy', Reworking (and Reproducing) Dominant Ideals' is uncovered, outlining alternative posts by the women that offer resistance to the dominant discourse, however examples are infrequent and lack evidence of conscious and overt politicisation. Future research should focus on pregnant women's self-interpretations of social media engagement and the pregnant bodies excluded from this discourse.
\end{abstract}

\section{Introduction}

The spoils of privilege have afforded for many, expectations of diverse, accessible leisure practices. In the global North we rely on being online during our waking hours, with portable digital devices becoming ubiquitous (Lupton, 2014). Cultural shifts have actively transformed “areas of life into leisure pursuits in unprecedented ways” (Lupton, 2016, p. 709) increasing the scope and dimensions of leisure studies. Our leisure rhythms now include: regular online shopping and in-app purchases; Internet video-calls and gaming, daily web-browsing, and 
hourly social media checks made possible by constant immediate access to a digital form of leisure. Conceptualised as ‘Digital Leisure’ (Spracklen, 2015), practices show remarkable parallels with traditional leisure; it's where experiences are lived, identities and networks of belonging are constructed, and power imbalances are reproduced and resisted.

Social media is an online space where digital leisure allows us to engage with the world and construct and maintain identities. Instagram (with over 400 million users (Instagram, 2016)) is a distinctive channel in that the focus is on sharing and consuming images or 'snapshot photography’ often focussing on leisure activities and happy moments (Kotchemidova, 2005). Generally, self-selected images are uploaded in which individual's selves are portrayed in an attractive light (Manago Graham, Greenfield, \& Salimkhan, 2008). Predominantly used as a mobile application, it offers users the opportunity to adjust, sharpen, crop, lighten, and apply filters to images to distort reality into an ideal to be shared. Users are able to 'like' a picture which helps inform their future browsing for content. This can be viewed as an endorsement, validation or popularity (Chua \& Chang, 2016). Users are therefore exposed to multiple ‘idealised’ images of peers as well as other people or organisations (with public accounts) actively shaping visual ideas about beauty regarding ‘acceptable’ bodies.

As our lives and experiences move online, our (leisured) bodies are becoming hybrid bodies (Lupton, 2015) where “technologies, media and lives” are bound as one (Ringrose \& Harvey, 2017, p. 452). These cannot be fully understood without recognition and exploration of the digital technologies that constitute their embodiment. Within the context of digital leisure, a space is created where the socially constructed and disciplined "body (shaped, sculpted, 
manicured and governed) is displayed (see Foucault, 1997) publically and not just to [virtual] friends” (Silk, Millington, Rich \& Bush, 2016, p.712) for examination. Bodies are created and maintained which blur lines between the digital and physical (Silk et al., 2016), thus, our bodies are becoming cyborgs that symbolise a fusion of the digital and fleshy (Francombe, 2010, 2014; Francombe-Webb 2016; Francombe-Webb \& Silk 2016). To this end, it is imperative to explore how digital cultures regulate the bodies that are scrutinized, shaped and exist within them.

As with the fleshy body, not all digital hybrid bodies are regulated consistently. Gender norms have been transferred to digital leisure spaces (Van Doorn, Wyatt \& Van Zoonen, 2008) promoting the emergence of hyper-feminine (often sexualised) digital, fleshy bodies (Silk et al., 2016). Ringrose \& Harvey (2015) highlight that social networking sites are leisure spaces in which gendered discourses are performed through digital images and women's bodies are subject to high levels of regulation. In addition there are within-gender variances in how these bodies are governed based on age, race, class and in terms of life stage (e.g. pregnancy).

\section{Digital Pregnant Bodies}

During pregnancy women are subjected to medical (Harper \& Rail, 2011; Jette \& Rail, 2013) and cultural (Brubaker, 2007; Dworkin \& Wachs, 2004; Earle, 2003; Marshall \& Woollett, 2000; Morris \& McInerney, 2010; Sha \& Kirkman, 2000) discourses relating to the 'ideal' body that promote self-regulation and provide insights into body dissatisfaction for women (Astrachan-Fletcher, Veldhuis, Lively, Fowler, \& Marcks, 2008; Nicolson, Fox, \& Heffernan, 2010; Rudolf, \& Feltbower, 2015). Research exploring the aesthetic self-surveillance of women's bodies through bump culture demonstrates pregnant women are subjected to 
normalised images of perfect pregnant bodies that communicate unrealistic ideals (Brubaker, 2007; Dworkin \& Wachs, 2004; Earle, 2003; Marshall \& Woollett, 2000; Morris \& McInerney, 2010; Sha \& Kirkman, 2009). This is compounded by dominant medical discourse surrounding ‘appropriate’ weight gain during pregnancy (Jette \& Rail, 2013) subjecting women to an external gaze and associated scrutiny (Harper \& Rail, 2011). Furthermore, increasingly pregnant women are subjected to a postfeminist rhetoric that communicated contradictory and unrealistic ideology regarding the 'ideal’ pregnant body, which must be soft, natural, yet fit and toned (Markula, 1995). Exploring women’s body image anxieties during pregnancy is of critical importance as it is related to negative health outcomes such as post-natal depression (Downs, DiNallo, \& Kirner, 2008), and long-term negative body image (Sumner, Waller, Killick, Elstein, 1993).

Pregnancy experience is increasingly shifting online (Lupton, 2016) with pregnant women increasing the visibility of their bodies by deliberately using identifiable hashtags to actively engage with the attention economy of social media (Marwick, 2015). This practice contradicts previous research that suggests that pregnant women feel a need to conceal their potentially problematic bodies (Nicolson et al., 2010). Lupton (2012) highlights that the pregnant body is a public figure, on display for others to comment on in ways not considered appropriate for other bodies. Therefore pregnant women who share their bodies through Instagram are choosing to make their bodies even more publically available, and well as subjecting their bodies to self-discipline, they are further disciplined by the reactions (likes, shares etc.) of others, creating the social body. Lock and Scheper-Hughes (1990) explain that the body politic maintains stability through its ability to regulate social bodies and discipline individual bodies. Instagram as a highly culturally communicative and visual platform is therefore a pervasive context in which to explore body discipline and regulation. 
Although there is a research narrative supporting the notion that pregnancy can be a time where women are more likely to experience pressure to conform to normative physical standards, this relationship is not simple (Gonçalves, Freitas, Freitas-Rosa, \& Machado, 2015; Harper \& Rail 2011). Pregnancy can be empowering (as well as restricting) for women (Sawicki, 1999) as it could be argued that society privileges the pregnant form. In this sense, pregnancy releases women for the expectation to conform to a thin ideal (Bedor \& Tajima, 2012), or "tyranny of slenderness" (p.250) creating a space where women can enjoy a more embodied maternal identity (Earle, 2003). Thus pregnancy may provide an empowering counterpoint to western ideals of slimness.

\section{Digital Pregnant Bodies as Activism}

Whilst pregnancy may be viewed as a pathway to empowering embodiment (Bedor \& Tajima, 2012; Earle, 2003) it is unclear whether this is restricted within digital leisure contexts such as Instagram, as they enhance the communication of unrealistic ideals (Brown \& Tiggeman, 2016; Santarossa et al., 2016). However, Chawansky (2016) suggests Instagram provides opportunities for 'digital activism' (within the context of LGBT athletes) by promoting visibility of underrepresented individuals. A review of the platform's content shows evidence of women adopting empowering hashtags to identify posts such as \#EFFYourBeautyStandards; \#HonorMyCurves; \#CelebrateMySize and \#AlternativeCurves to demonstrate alternative images of femininity and increase visibility of culturally lessprivileged bodies. Therefore, pregnant women have the opportunity for agency by increasing the visibility of their aesthetically problematic bodies (Dworkin \& Wachs, 2004; Willmott, 2013), and resisting dominant discourse by displaying unfiltered images of large, soft, 
pregnant bodies with markings of pregnancy such as stretch marks, loose skin and prominent veins.

The $4^{\text {th }}$ Trimester Body Project which aims to 'celebrate the uncensored beauty of motherhood' by educating and empowering people through images and storytelling has over 47,000 followers on Instagram, and their associated \#stopcensoringmotherhood campaign has over 25,000 posts associated with pregnancy, birth and post-natal experience. Campaigns meet the call for "more alternative and transgressive subject positions to better represent the complex and varied experiences of pregnant women” (Harper \& Rail, 2011, p.12.). These allow for more varied and realistic constructions of the pregnant subject, drawing upon feminist post-structuralist theory which views pregnant bodies as socially constructed through cultural practices such as discourse (Rail 2002; Weedon 1997). This approach sees women as being able to resist traditional discourse on the pregnant body (Jette \& Rail, 2013) and promises change by challenging the oppression of women and improving conditions through research (Sprague, 2005). Ultimately, social media platforms have potential to challenge normative assumptions about pregnant bodies and afford (some individuals) some freedoms. Furthermore, the interactivity and pace of digital leisure can potentially make it more culturally communicative than traditional forms of leisure (Spracklen, 2015) allowing it the potential to be a powerful vehicle for change.

Increasingly, research exploring the experience of pregnant women questions dominant discourses of power (Jette, 2011 \& Jette \& Rail 2013 see also Foucault, 1988), and disrupts these by addressing the way we communicate ideas (discursive ways) and the way we do things (practical ways) (See Markula 2014). This allows digital leisure to be viewed as a site of both normative reproduction AND challenge, and facilitates questioning on how digital leisure platforms such as Instagram could be used to capture pregnancy in a less normative tone. In a recent special issue editorial on digital leisure, Silk et al. (2016) call for work that 
actively challenges 'sites of injustice and inequity engrained within digital leisure cultures' (p.718) and helps develop our understanding of how digital leisure cultures control, govern and regulate citizens and their bodies. They call for critical questioning regarding how digital leisure celebrates and pathologises bodies, and work that explores which bodies matter and are visible (and those which are less visible) within digital culture. In adopting a critical framework, the current research can contribute to both exploration and action. This research will consider that Instagram images generally portray an enviable elite lifestyle and hegemonic (white, heterosexual) ideals about beauty. These representations of the normalised pregnant body are exclusive and as such can be disruptive for all pregnant women. It is therefore essential that research focusses on how digital leisure impacts how pregnant women experience their bodies in multiple contexts, as well as actively addressing which types of pregnant bodies are visible.

\section{Method}

Research that uses Instagram posts as units of analysis generally adopts a quantitative or mixed approach (Doring et al 2016; Hu et al. 2014; Manikonda et al 2014; Smith \& Sanderson 2015; Ward 2016). However, this study utilised discourse analysis in to explore dominant discourse surrounding pregnant women’s bodies apparent through self-presentation on Instagram, and explore potential areas of challenge and resistance. It is unique in that it adopts a more inductive framework, allowing for exploration of the richness of the phenomenon, thus having implications for content selection and analysis.

\section{Content Selection}


Content was selected from user-generated posts on Instagram, including visual and textual data in the form of photographic posts and the text from the post author accompanying these. Whilst there was additional data (hashtags and comments from other users) analysis of this was not aligned with the study objectives. However, as with existing research (Pila et al., 2017; Tiidenberg, 2015) hashtags were used as identifying labels to obtain relevant content. To obtain posts relating to the self-presentation of the pregnant female body, popular hashtags relating to this theme were identified. Instagram analytics (number of occurrences of hashtag identified in Instagram search bar), and a review of the associated content, the following hashtags were selected as they yielded information rich cases in line with sampling for qualitative research studies: \#pregnant $(6,723,539$ posts) \#pregnancy $(4,708,900)$ \#preggo $(1,084,398)$ \#firsttrimester $(53,902)$ \#secondtrimester $(143,245)$ \#thirdtrimester $(369,857)$. Instagram posts were used to identify relevant accounts that met the inclusion criteria (Table 1) which could be explored in depth by the researcher. Accounts were identified in this way until a point of data saturation had been reached.

Table 1

Inclusion Criteria

\begin{tabular}{|l|}
\hline \multicolumn{1}{|c|}{ Criteria } \\
\hline Public accounts \\
\hline Pregnant women \\
\hline Posting photographic data and text on their own feed \\
\hline English speaking \\
\hline
\end{tabular}

Only posts containing image data (as opposed to video posts) were included in line with the analytical approach. To meet the study’s aims of exploring self-representation, and to 
negotiate potential ethical issues images needed to be of pregnant women's own bodies from personal accounts. Many posts were excluded as they were from companies marketing pregnancy related goods and services or from users compiling pictures of pregnant women (including pornographic images). To further negotiate ethical issues, the accounts needed to be public. Finally, only posts from English-speaking women (confirmed by accompanying text) were included so that the captions alongside the photos could be analysed.

60 posts were identified as meeting the criteria from the public accounts of 16 pregnant women . These were posted in five countries: the USA (9), the UK (4), Australia (1), Belgium (1) and Canada (1). The posts were continually sampled until there was significant and consistent repetition of themes. The image and caption data from these posts were then imported into Nvivo 10 for coding and analysis. Each of the participant’s Instagram identifying names (handles) has been changed from the original to protect anonymity. Furthermore, direct quotations have been paraphrased throughout so that they don't serve to identify users.

\section{Discourse Analysis}

Discourse analysis views bodies as created through language (Harper and Rail, 2011) therefore the coding process requires engagement with the language and exploration of the truths given by their repetition. The analysis process was conducted in three stages in line with the approach outlined by Howarth (2000). Firstly was a process of 'translation' where the Instagram posts and accompanying images were translated into textual form using the 'region' and 'content' tools on Nvivo 10. This leads the researcher to immerse themselves and to develop a sense of the whole text. Secondly the theoretical perspectives were applied 
to the textual data, involving the 'articulation and modification of abstract concepts' (Howarth, 2000, p. 141). This stage examines the ways in which the objects under study (in this case the pregnant body) are constructed in the text. Finally, a further layer of analysis associated with both Foucauldian and post-structualist discourse analysis (Jette \& Rail, 2013) were deployed including the critical questioning of positioning, and practices of power (Georgaca \& Avdi, 2011) as well as considering potential for challenge and change within these contexts. Key themes were then derived from this initial coding process by grouping coded data based on content using the philosophical lens of Foucauldian analysis and feminist post-structualist theory. Once themes were identified they were second checked by a research colleague with experience in discourse analysis and online research methods to enhance the overall rigour of the study.

\section{Results and Discussion}

\section{The 'Perfect Pregnancy' and Middle-class, Consumptive Ethic}

The accounts were oft dedicated to the reinforcement of dominant discourse through bodily practices surrounding how to do pregnancy 'well' or the 'perfect' pregnancy echoing notions of 'living properly' (Bonner 2008, p. 549) as culturally pervasive corporeal manifestations of a neoliberal body aesthetic. To conform the women needed bodies constructed in-line with ideals through the consumption numerous goods and services.

In line with symbolism of a good, enviable life, images within our data were often well-lit and professional looking shots of groomed (nearly exclusively) white pregnant bodies adorned with maternity fashion, often consuming obscure 'super foods'. These bodies were 
artistically arranged, and set to the backdrop of spotlessly clean, well-manicured homes or in exotic \#babymoon locations. The images and text told the story of how to have a 'successful pregnant body' built on the concepts of commodification, exclusivity, consumption, and the pursuit of 'perfection'.

This echoes the notion of 'living properly' and consumptive ethic outlined by Silk, Francombe and Bachelor (2011) who describe this process as the consumption and positioning of one's self as middle class tastes, lifestyles and values as a normative ideal. Thus, the posts demean working and lower class preferences, and regulate those who fail to conform to a middle class consumptive ethic (Bonner 2008; McRobbie, 2004; Ringrose \& Walkerdine 2008; Silk, Francombe \& Batchelor, 2011).

Many posts demonstrated bodily commodification to the extent to which the images and accompanying text read like media advertisements (often posts were sponsored). These posts emphasised consumption as a vital aspect of doing pregnancy 'well'. In this sense the discourse surrounding the perfect pregnant body is ‘classed’ (in addition to being heteronormative and racially exclusive) in rendering those without the means to engage in these practices as less visible and less relevant. @poshmama986 posted an image of herself dressed in an elaborate gown walking along a beautiful beach with the caption:

Oh wow thank goodness... we've arrived in Babymoon Nirvana... I feel like a pregnant princess!! So excited for3 days of pampering at @xxxhotel . 
As with the other forms of consumption outlined above, the notion of the 'babymoon' and 'pampering' creates a classed pregnant body afforded the luxury of time and space. Other posts made by @poshmama986 demonstrate her modelling a vast selection of maternity fashion clothing, images of her holding extravagant bouquets of fresh flowers, and posed on luxurious home furnishings. This paints an exclusive, 'classed' picture of pregnancy perfection that is unobtainable to most, and reiterates "the positioning of middle class tastes (literally) lifestyles and values as normative” (Silk, Francombe, \& Bachelor, 2011, p.16).

The level of bodily commodification and lines between the 'authentic' and 'advertised' are blurred further by some women, who’s personal accounts actively and purposively encourage pregnant women to engage in consumption to construct 'perfect' pregnant bodies. In yet another post showing a perfectly polished white woman walking along a beautiful beach (bodies in nature seemed to also be a theme of pregnancy perfection) @melissajaysmith captions:

This morning after a doctors appointment and Damien and I walked around the beach and ate the most delicious acai bowls...I somehow squeezed this belly into this cute dress that's under 30 dollars $\square$ ! To shop my look sign up for @liketoknow.it It is an easy way for you to shop via Instagram.

This quotation demonstrates how the platform design facilitates consumerism and reinforces neoliberalist ethics. The aesthetic focus of Instagram allows it to be the perfect partner platform to market goods and services by cashing in on the neoliberal turn toward the individual, and bringing previously non-comodifiable aspects of personal identity into the marketplace, turning lifestyle into gods and labour. 
Whilst the theme of 'perfect' pregnancy reflects culturally prevalent pregnancy ideals, it is important to note that these may be exaggerated within the research context as Instagram is designed in a way that facilitates consumer-driven visual marketing of goods and services. Instagram specifically facilitates collaborations between the personal accounts of users with significant followings and companies selling goods and services looking to increase their visual advertising reach. Applications such as LIKEtoKNOW.it allow users to 'shop' products from other Instagram user’s posts (if the user also has the app and has been approved by the organisations ‘secretive' selection process). In this sense pregnant bodies may actually become an active and purposeful advertisement, actively reinforcing the consumptive ethic (Bonner 2008; McRobbie, 2004; Ringrose \& Walkerdine 2008; Silk, Francombe and Batchelor, 2011). The Instagram posts reconstitute the way in which women's pregnant bodies are being presented as being in constant need of consumer spending to conform to increasingly narrow judgements of female attractiveness, and highlight the oppressive power in the form of consumptive ethic.

Examples of alternative consumptive patterns (for example working class consumption) were absent from our data. This is somewhat unsurprising as Instagram is utilised disproportionately for displays of middle class lifestyle and consumption (Abidin, 2016; Marwick, 2015). However, other research on pregnancy and Instagram, has demonstrated rare examples of how less economically privileged pregnant women may engage with the platform (Tiidenberg \&Baym, 2017). Tiidenberg and Baym saw examples of pregnant women 'wishlisting' or 'thrifting' on Instagram, reflecting an alternative yet aspirational class consumptive ethic. Their research also demonstrated that the pregnant women on 
Instagram within their sample who could not afford to purchase goods to reinforce the notion of a perfect pregnancy would be more likely to reinforce other ways in which they performed a 'responsible pregnancy' (p.10) for example through additional declarations of love, or playing classical music to the foetus. Despite this, the 'living properly' consumptive ethic associated with middle-class and aspirational higher-class sensibilities is clearly dominant on Instagram, imposed throughout dominant discourse surrounding these women's bodies.

The 'perfect pregnancy' in this context demonstrated a culturally consistent ideal that was communicated to and policed by the pregnant women, that was both class and race specific Depictions of the normalised citizen are bound in within the Instagram accounts of pregnant women with power relations characteristic in the presentation of bodies; particularly with regard to the assumptions about the relationship between class, race, gender, and, pregnancy.

\section{Doing Exclusive Heteronormative Pregnant Femininity}

The nearly exclusively (it was presumed that one woman would classify as multiracial) white women were often posed in romantic embraces with (exclusively) male partners, and/or their children, further reinforced by loving sentiments displayed in captions. In an artistically arranged, professionally looking photograph@belgianmamaproud shares a silhouetted image of herself and her partner in an embrace, foreheads touching and bump prominent between them set to the backdrop of the Dubai desert with the caption:

Couples that are meant to be are the ones who go through everything designed to tear them apart and come out stronger". I think this quote sums up our relationship pretty well... What better day today to remind you how much I love you 
Similarly, @melissajaysmith shares an image of her and her partner embracing on a beach (again in a beautiful gown but this time adorned with fresh foliage) alongside the declaration:

Thinking about this man that I love so much becoming a daddy seriously makes me want to cry

@miss.hubermat posted a number of individual images of posing in lingerie with cleavage exposed, as well as photos of her wearing exposing outfits in embraces with her partner who proudly caresses her body. She was also one of the many women who shared photos where their hair was perfectly styled, make-up done, nails painted, and bodies adorned with glamorous accessories.

These posts revealed presentations of specific kind of 'proper' heterosexual femininity in line with the assumption of 'compulsory heterosexuality’ (Rich, 1980), which showed women relationally through their husbands. These women emphasise their femininity in an attempt to fit into the hetero-sexy norms maintained and policed within digital cultures, and avoid discrimination, yet simultaneously risk being overly sexualised and trivialized. Therefore in this context digital leisure cultures do little to emancipate women from oppressive notions of pregnant sexual hetero-normative femininity.

Tiidenberg (2015) also discusses the cultural importance of Russian women being 'motherly' and 'beautiful' as well as 'wifely' (p.1748) to reinforce (and embody) emphasized femininity. Whilst the Russian woman reinforced their heteronormative femininity performativity by sharing images of them 'waiting' for their husbands to come home, the women in this research embodied discourse through the use of highly-sexual poses such as pouting and positioning the exposed body with open legs. Whilst this relational identity was more 
apparent in Tiidenberg's 2015 research, there were clear comparisons within the current study. Only heterosexual relationships were referenced within the posts in line with the heteronormative theoretical framework. Herman (2003) defines heteronormativity as more than just the construction of a norm. He argues that it also provides ' ...the perspective through which we know and understand gender and sexuality in popular culture' (p. 144) requiring compliance to dominant discourse (Dymock, 2011). The compliance to heteronormative discourse surrounding the pregnant body is one such example of this. This demonstrates parallels to the findings from Tiidenberg's (2015) study on the self-presentation of pregnant Russian Women through their Instagram accounts who also found that these women cast themselves as loving wives and partners.

Despite the accounts coming from diverse contexts, both the women in the current study, and Tiidenberg’s research emphasise normative self-presentations of femininity and heteronormativity. This reinforces neo-liberalist ethic which unites gender, sex and gendered identities through (hetero)normative discourse surrounding 'compulsory heterosexuality' (Rich, 1980) where notions of sex and sexuality are propagated through sexualisation and other regulatory discursive processes (Griffin, 2007).

In this research the women's bodies, although visibly pregnant were also taught and toned, in line with existing research (Harper \& Rail, 2011 and Jette \& Rail, 2013) which suggests that pregnant women are disciplined by dominant discourse on obesity which privileges the slender yet toned 'post-feminist' pregnant body and contributes to the aesthetic surveillance of women. The current research also showed women reinforcing 'motherly qualities' with many women sharing images of themselves staring down lovingly and touching their bumps alongside text reinforcing feelings of happiness and love. Women also shared images of 
themselves and their current children (generally immaculately presented in co-ordinated baby fashion), casting themselves further as in the idealised motherly role. Thus, through their Instagram posts the pregnant women reinforced hegemonic gender roles stereotypes relating to both femininity (passive, dependent and maternal) and masculinity (dominant \& independent) that can sustain sexism and the oppression of women (Bartky, 1990). This theme therefore demonstrated clear cross-cultural trends between the sample of Englishspeaking western women in the current study and Russian women in Tiidenberg's 2015 research in terms of the relational identities of pregnant women.

\section{Self-surveillance \& Hyper-visibility of the Digital Fleshy Pregnant Body}

Women were embodying dominant discourse regarding neo-liberalism, consumption, traditional medicine, heteronormativity, and hegemonic masculinity, and used this to engage in self-surveillance, policing, and monitoring of their pregnant bodies. Not only did they embody these messages, but they also demonstrated engaging in obsessive surveillance. One common practice employed by women in the current study was to post images of their pregnant bodies under text and images outlining the normative (assumed) size of their baby in comparison to certain recognisable foods. For example @andipanda33shows her heavily pregnant body and protruding baby bump underneath text stating '38 WEEKS BABY IS THE SIZE OF A CAKE' with a drawing of a cake. Not only do these images demonstrate that the women are engaging in self-surveillance in terms of regulating their changing bodies, but the comparison to common foods show an embodiment of medical discourse surrounding baby growth 'centile' lines which represent the level of growth that is considered 'normal' and appropriate for babies. 
In another image set underneath text, @happijan1 posted a picture of her headless body and prominent baby bump under the caption 'Feeling Huge' with the caption 'I feel like an overinflated balloon and there’s still 10 weeks to go’. Further posts by @happijan1 show comparison pictures of her body at different sizes with the caption:

Here I was already 20+ lbs down from my highest weight of $270+$ In the middle was my lowest weight, after my wedding, more muscular and fit than I've ever been in my life. On the right was yesterday at 7 months pregnant and feeling fab! I can't wait to have this baby girl and get back to my pre-pregnancy weight and lower!

These posts demonstrate obsessive self-surveillance, policing, monitoring and re-shaping of the body through digital leisure, and embodiment of the dominant obesity discourse regarding ‘appropriate’ weight gain during pregnancy (Jette \& Rail, 2013 \& Harper \& Rail 2011). The posts highlight the pressure placed on pregnant women to adhere to guidelines surrounding the normative size to be to have a 'healthy' pregnancy, as well as the pressure to return to pre-pregnancy weight (or lower) with haste.

Another theme of the photographic images was the level of hypervisibility of pregnant bodies. Many of the images showed women in various stages of undress exposing their bare stomachs, (and occasionally their legs and cleavages). Academics have noted that digital leisure actively promotes bodily exposure, and a level of hyper-visibility of the frequently hyper-feminine ‘digital/fleshy body’ (Silk et al 2016, p. 718). Digital leisure, especially in the form of image-led social media, facilitates an environment that normalises hypervisibility 
of (frequently but not exclusively) female bodies in multiple contexts, with pregnant bodies being no exception. This increased visibility opens these bodies up to increased surveillance (including self-surveillance) and scrutiny.

\section{Rejecting the 'Perfect Pregnancy', Reworking (and Reproducing) Dominant Ideals}

Whilst the ideology of the 'perfect pregnancy' was visibly dominant, analysis also showed examples of pregnant women rejecting this form of self-presentation, 'opting out' of the race to present a disciplined body that complies with dominant discourse. This could be identified as a form of 'digital activism' similar to that outlined by Chawansky (2016). These posts provide increased visibility for a greater range of "more alternative and transgressive subject positions to better represent the complex and varied experiences of pregnant women” (Harper \& Rail, 2011, p.12.) and (potentially) allow for more empowering constructions of the pregnant subject. For example, @andipanda33shared various ‘unfiltered’ images on Instagram throughout her pregnancy showing her stretch marks with captions such as 'embracing it', as well as natural images of her relaxing and pulling faces in casual clothing on the sofa. Images of bellies covered in stretch marks were also posted by @heidimamaxxx with captions like 'tigerstripes'. This demonstrated an alternative, raw, fleshy image of pregnancy that contrasts the common 'rosy-glow' images that represent women's pregnant bodies on Instagram.

Furthermore, whilst the above themes demonstrated that most of the women used Instagram as a tool to reinforce heteronormative notions of femininity, and their identity as loving partners and mothers, some pregnant woman used it as a way to reinforce alternative, 
personal leisure-based identities that cast them as individuals as well as being relational. @fit_mimi88 posted numerous images of her muscular pregnant body, including images of herself heavily pregnant in bodybuilding poses, accompanied by text such as:

My back is looking thicker!

Whilst @fit_mimi88 is clearly pregnant within many of the images with an exposed baby bump, she is not referring to her pregnancy within many of the captions. This suggests that as opposed to the many instances of pregnant women using Instagram to reinforce their pregnant relational identities, women are also using it to reinforce alternative and more individualised identities. In a rare post where @fit_mimi88 does discuss her pregnancy, she shares an image of her exposed bump sat neatly under rippling abdominals and posts the following text:

Trying to keep the obliques and maintain this level of bodyfat for the rest of this pregnancy. After the baby comes I won't be able to exercise a whole lot before my wedding and I want to look and feel like myself on that special day. It might seem that this is something that shouldn't be extremely important at this point but who doesn't want to look and feel their best on their wedding day!? And who says you can't be the prego lady with abs?

By posting images of muscular pregnant bodies, @fit_mimi88 uses Instagram as a political vehicle to increase visibility of 'alternative' pregnant bodies, and pose resistance to 
oppressive dominant discourses that surround pregnancy. However, whilst these images demonstrate a transgression from the normative image of the pregnant body, academics have suggested that norms surrounding the pregnant body are shifting. Being slim is no longer enough, today women also have to be muscular (Guendouzi, 2004; Holland and Tiggemann, 2016; Tiggemann and Zaccardo, 2016 also see Santarossa et al 2016) forcing us to view socially constructed pregnant bodies through constantly changing interpretive frameworks and shifting ideologies (Hanson, 2004). Therefore hyper-fit pregnant bodies may be contributing to culturally reformed discourse surrounding pregnancy. Jette (2011) argues that discourse surrounding fit pregnancy has the “potential to shape women’s subjective experience of pregnancy and exercise' and 'turning it into a guilt- and anxiety-ridden excursion”(p. 307). This growing body of research suggests that pregnant women are being pressured to self-discipline to have a "fit pregnant body with a taut, tight 'bump" (Nash, 2011, p.50). Therefore it could be argued that pregnant women demonstrating muscularity may be engaging in dis-empowering practices and reinforcing oppressive ideologies as opposed to challenging them. This reiterates post-feminist scholarship that identifies the problematic assumption regarding how women unknowingly perpetuate mediated ideals (Brook, 2008; Markula, 1995 see also Bedor and Tajima, 2012).

Whilst@@fit_mimi88 demonstrates significant muscularity through her Instagram pictures, and a desire to maintain an individualised body subject, the post text reiterates her relational identity as a partner, as well as a pressure to look appealing on her wedding day. @fit_mimi88 is therefore engaging in bodily self-surveillance to maintain her identity, demonstrating that her body is constructed in line with dominant discourse. Whilst @fit_mimi88 identifies that her attitude towards her body may oppose normative ideals of pregnancy by stating 'It might seem to some of you that this is something that shouldn't be 
extremely important at this point', she is visibly still engaging in self-surveillance and body discipline based on the ideologies that will be imposed upon her post-pregnancy.

In a particularly revealing post @mrshelen2014, an Instagram user who regularly posts artistic images of her pregnant body engaged in complex yoga poses, reveals a contrasting unfiltered image of her pregnant belly strapped into a harness, accompanied by the following text:

For those of you who have wished or secretly scorned me to your partner about how great I've been feeling pregnant and how I must be full of crap and I'm so annoying for the past 34 weeks (I don't take it Personal. It's natural and we all do it), this post is for you. It has happened! Today, I'm uncomfortable... So, yey to those of you who have thought "how is she still getting her leg up in that position?" I am flawed and struggling with every other pregnant girl today.

Whilst the majority of @mrshelen2014’s posts communicate dominant discourse relating to the notion of 'perfect pregnancy' and reinforce that argument that pregnant women being pressured to self-discipline to have a "fit pregnant body with a taut, tight 'bump"” (Nash, 2011, p.50) this post provides a clear contrast that actively recognises both the competitive pressure placed on pregnant women, as well as exposing the stark physical realities of being pregnant. Her posts provide an example of how Instagram can be used as both a tool to communicate 'rosy' normative ideals, as well as vehicle to increase the visibility of bodies that don’t comply, thus challenging normalisation.

\section{Conclusion}

The analysis demonstrates that pregnant women embody dominant discourse regarding neoliberalism, consumption, traditional medicine, heteronormativity, and hegemonic masculinity, 
and use this discourse to engage in self-surveillance, policing, and monitoring of their pregnant bodies. Despite this some women posted 'alternative' images that offered resistance to the dominant discourse. These examples were infrequent and lacked evidence of conscious and overt politicisation, therefore calling into question the extent to which they could be considered as a form of 'digital activism’ as outlined by Chawansky (2016). It was also unclear to what extent the pregnant women in this sample are passively subjected to dominant discourse as opposed to using the democratising power of social media to self-consciously construct and capitalise on notions of the perfect pregnancy. Thus the research has uncovered the complexities that exist in how pregnant women present their bodies on Instagram in terms of reproducing and reinforcing notions of 'perfect pregnancy'.

To explore these complexities further, there is a need for research to explore the livedexperiences of pregnant women who engage with Instagram as digital leisure. Research that includes the hashtags used by pregnant women as data may help provide depth, and understanding of pregnant women's intentions and interpretations, however direct engagement through qualitative interviewing or (net)ethnographic methods would facilitate greater depth, and help explore the extent to which pregnant women engaging with the Instagram platform are active agents in the construction of dominant ideals. This would allow for exploration of the constantly shifting interpretive frameworks (Hanson, 2004), and question the notion of a consistent, socially prevalent 'ideal' pregnant body. It would also help explore whether 'fit-pregnancy' is a reformed oppressive ideal reflective of a postfeminist era. In line with Cummins’s (2014) suggestion that pregnant women may experience empowerment through dominant discourse, it could help explore the potential for women to gain positive experiences, and personal empowerment through (as opposed to being in spite) of discourse. For example, neo-liberalist ideals surrounding consumerism that 
are clear through the 'perfect pregnancy' discourse may bring joy to pregnant women by encouraging them to consume maternity, and pregnancy related goods that are personally meaningful. Social media specifically may allow for a democratisation of power that allows pregnant women to actively shape culture by engaging with platforms such as Instagram. Therefore whilst content and discourse analysis approaches are valuable in this context, it is imperative that future research explores in-depth experiences of pregnant women engaging in digital leisure.

Whilst the analysis indicated a lack of visibility of types of pregnant bodies (e.g. LGBT, black, or disabled bodies), this was not explored in depth. Future research should focus on pregnant bodies that are absent on this platform to explore the disparities that exist. Such research would provide a clearer understanding of the form of heteronomativity and dominant discourse being reinforced through Instagram. .Whilst disconfirming cases are surely available, it was clear from the research that these lacked general visibility on Instagram. Further research to uncover such examples may provide insight into the democratisation of digital spaces, digital activism, and help explore a broader range of pregnant digital identities. Although it was touched upon within the themes incorporating 'exclusive consumption and 'perfect pregnancy' within the current study, there is also a need to address more specifically the intersections with the dominant discourse and class and culture to understand inequalities. Further research should also focus on the cross-cultural similarities and differences regarding the 'perfect' pregnancy ideal communicated on aesthetically driven social media platforms, and address the the limitations relating to geographical locations of study participants within the current research (USA (9), the UK (4), Australia (1), Belgium (1) and Canada (1)). Social media contributes to, and reflects a global society involving pregnant women from a variety of different cultural backgrounds. In this sense it is likely to facilitate shared experiences, 
whilst also reflecting historical differences in women's experiences that impact notions of the 'perfect' pregnant body.

\section{References}

Abidin, C. (2016). “Aren’t these just young, rich women doing vain things online?”: Influencer selfies as subversive frivolity. Social Media and Society, 2, 1-17.

Astrachan-Fletcher, E., Veldhuis, C., Lively, N., Fowler, C., \& Marcks, B. (2008). The reciprocal effects of eating disorders and the postpartum period: a review of the literature and recommendations for clinical care. Journal of Women's Health, 17(2), 227-239.

Bartky, S. L. (1990). Femininity and domination: Studies in the phenomenology of oppression. New York, NY: Routledge

Bedor, E., \& Tajima, A. (2012). No Fat Moms! Celebrity Mothers' Weight-Loss Narratives in People Magazine. Journal of Magazine \& New Media Research, 13(2), 1-26.

Bonner, F. (2008). Fixing relationships in 2-4-1 transformations. Continuum: Journal of Media \& Cultural Studies, 22(4), 547-557.

Brown, Z., \& Tiggemann, M. (2016). Attractive celebrity and peer images on Instagram: Effect on women's mood and body image. Body Image, 19, 37-43.

Brubaker, S. J. (2007). Denied, Embracing, and Resisting Medicalization African American Teen Mothers' Perceptions of Formal Pregnancy and Childbirth Care. Gender \& Society, 21(4), 528-552. 
Chawansky, M. (2016). Be who you are and be proud: Brittney Griner, intersectional invisibility and digital possibilities for lesbian sporting celebrity. Leisure Studies, 35(6), 771782.

Chua, T. H. H., \& Chang, L. (2016). Follow me and like my beautiful selfies: Singapore teenage girls’ engagement in self-presentation and peer comparison on social media. Computers in Human Behavior, 55, 190-197.

Cummins, M. W. (2014). Reproductive Surveillance: The Making of Pregnant Docile Bodies. Kaleidoscope, 13, 33.

Devine C, Bove C, \& Olson C. (2000). Continuity and change in women’s weight orientations and lifestyle practices through pregnancy and the postpartum period: The influence of life course trajectories and transitional events. Social Science and Medicine, 50(4), 567-82.

Downs, D. S., DiNallo, J. M., \& Kirner, T. L. (2008). Determinants of pregnancy and postpartum depression: prospective influences of depressive symptoms, body image satisfaction, and exercise behavior. Annals of Behavioral Medicine, 36(1), 54.

Dworkin, S. L., \& Wachs, F. L. (2004). “Getting your body back”: Post-industrial fit motherhood in shape fit pregnancy magazine. Gender \& Society, 18(5), 610-624.

Dymock, A. (2011). But femsub is broken too! On the normalisation of BDSM and the problem of pleasure. Psychology \& Sexuality, 3(1), 1-15

Earle, S. (2003). “Bumps and boobs”: Fatness and women’s experiences of pregnancy. Women’s Studies International Forum, 26(3), 245-252. 
Foucault, M. (1977). Discipline and Punish. (A. Sheridan Trans.). New York, NY: Vintage

Foucault, M., Martin, L. H., Gutman, H., \& Hutton, P. H. (1988). Technologies of the self: A seminar with Michel Foucault. Univ of Massachusetts Press, 1988.

Francombe, J. (2010). 'I cheer, you cheer, we cheer’: Physical technologies and the normalized body. Television \& New Media,11, 350-366.

Francombe, J. (2014). Learning to leisure: Femininity and practices of the body. Leisure Studies, 33, 580-597.

Francombe-Webb, J. (2016). Critically encountering exer-games and young femininity. Television \& New Media, 17, 449-464.

Francombe-Webb, J., \& Silk, M. (2016). Young girls’ embodied experiences of femininity and social class. Sociology, 50, 652-672.

Georgaca, E., \& Avdi, E. (2011). Discourse analysis. In Harper, D., \& Thompson, A. R. (Eds.), Qualitative research methods in mental health and psychotherapy: A guide for students and practitioners (pp.147-162). Chichester,UK: John Wiley \& Sons.

Gonçalves, S., Freitas, F., Freitas-Rosa, M. A., \& Machado, B. C. (2015). Dysfunctional eating behaviour, psychological well-being and adaptation to pregnancy: A study with women in the third trimester of pregnancy. Journal of Health Psychology, 20(5), 535-542.

Griffin, P. (2007). Sexing the economy in a neo-liberal world order: Neo-liberal discourse and the (re) production of heteronormative heterosexuality. The British Journal of Politics and International Relations, 9(2), 220-238. 
Hanson, C. (2004). A Cultural History of Pregnancy: pregnancy, medicine and culture, 17502000. Basingstoke,UK: Palgrave.

Harper, E. A., \& Rail, G. (2011). Contesting “silhouettes of a pregnant belly”: young pregnant women's discursive constructions of the body. Aporia, 3(1), 5-14.

Herman, D. (2003). “'Bad Girls changed my life’’: Homonormativity in a women’s prison drama. Critical Studies in Media Communication, 20, 141159.

Howarth, D. (2000). Discourse. Buckingham , UK: Open University Press

Instagram (2016). Our story a quick walk through our history as a company. Retrieved from: http://instagram.com/press/

Jette, S. (2011). Exercising Caution: The Production of Medical Knowledge about Physical Exertion during Pregnancy. Canadian Bulletin of Medical History, 28(2), 293-313.

Jette, S., \& Rail, G. (2013). Ills from the womb? A critical examination of clinical guidelines for obesity in pregnancy. Health, 17(4), 407-421.

Kazmeirczak, M. and Goodwin, R. (2012). Pregnancy and body image in Poland: Gender roles and self-esteem during the third trimester. Journal of Reproductive and Infant Psychology , 29(4), 334-342.

Kotchemidova, C. (2005). Why we say “cheese”: Producing the smile in snapshot photography. Critical Studies in Media Communication, 22(1), 2-25.

Jette, S., \& Rail, G. (2013). Ills from the womb? A critical examination of clinical guidelines for obesity in pregnancy. Health, 17(4), 407-421. 
Lock, M., \& Scheper-Hughes, N. (1990). A critical-interpretive approach in medical anthropology: Rituals and routines of discipline and dissent. Medical anthropology: Contemporary theory and method, 3, 47-73.

Lupton, D. (2012). 'Precious cargo’: Foetal subjects, risk and reproductive citizenship. Critical Public Health, 22(3), 329-340.

Lupton, D. (2014). Digital sociology. Abingdon, UK: Routledge.

Lupton, D. (2016). Foreword: lively devices, lively data and lively leisure studies. Leisure Studies, 35(6), 709-711.

Marshall, H., \& Woollett, A. (2000). Fit to reproduce? The regulative role of pregnancy texts. Feminism \& Psychology, 10(3), 351-366.

Marwick, A. E. (2015). Instafame: Luxury selfies in the attention economy. Public Culture, 27(1 75), 137-160.

Manago, A. M., Graham, M. B., Greenfield, P. M., \& Salimkhan, G. (2008). Selfpresentation and gender on MySpace. Journal of Applied Developmental Psychology, 29(6), 446-458.

Markula, P. (1995). Firm but shapely, fit but sexy, strong but thin: The postmodern aerobicizing female bodies. Sociology of sport journal, 12(4), 424-453.

Markula, P. (2014). The moving body and social change. Cultural Studies? Critical Methodologies, 14(5), 483-495.

McRobbie, A. (2004). Notes on 'What Not To Wear' and post-feminist symbolic violence. The Sociological Review, 52(2), 97-109.

Morris, T., \& McInerney, K. (2010). Media representations of pregnancy and childbirth: an analysis of reality television programs in the United States. Birth, 37(2), 134-140. 
Nash, M. (2011). “You don't train for a marathon sitting on the couch”: Performances of pregnancy 'fitness' and 'good' motherhood in Melbourne, Australia. Women's studies International Forum, 34 (1), 50-65.

Nicolson, P., Fox, R., \& Heffernan, K. (2010). Constructions of Pregnant and Postnatal Embodiment across Three Generations Mothers’, Daughters' and Others’ Experiences of the Transition to Motherhood. Journal of health psychology, 15(4), 575-585.

Rail, G. (2002). Postmodernism and Sport Studies. In: J, Maguire \& K, Young (eds) Theory, Sport and Society. Oxford, UK: JAI Press, (pp.179-210).

Rich, A. (1980). Compulsory heterosexuality and lesbian existence. Signs: Journal of women in culture and society, 5(4), 631-660.

Ringrose, J., \& Harvey, L. (2015). Boobs, back-off, six packs and bits: Mediated body parts, gendered reward, and sexual shame in teens' sexting images. Continuum, 29(2), 205-217. Ringrose, J., \& Harvey, L. (2017). Digital Mediation, Connectivity, and Networked Teens. In Silk, M. L., Andrews, D. L., \& Thorpe, H. (Eds.). Routledge handbook of physical cultural studies. Abingdon,UK: Routledge.

Ringrose, J. \& Walkerdine, V. (2008). Regulating the Abject. Feminist Media Studies, 8(3), 227-246.

Santarossa, S., Coyne, P., Lisinski, C., \& Woodruff, S. J. (2016). \#fitspo on Instagram: A mixed-methods approach using Netlytic and photo analysis, uncovering the online discussion and author/image characteristics. Journal of Health Psychology, 1359105316676334.

Sawicki, J. (1999). Disciplining mothers: Feminism and the new reproductive technologies. In J. Price \& M. Shildrick (Eds.), Feminist theory and the body: A reader (pp. 190-202). New York, NY: Routledge 
Sha, J., \& Kirkman, M. (2009). Shaping pregnancy. Australian Feminist Studies, 24(61), 359-371.

Silk, M. L., Francombe, J., \& Bachelor, F. (2011). The Biggest Loser: The discursive constitution of fatness. Interactions: Studies in Communication \& Culture, 1(3), 369-389.

Silk, M., Millington, B., Rich, E., \& Bush, A. (2016). (Re-) thinking digital leisure. Leisure Studies,35, 712-723.

Spracklen, K. (2015). Digital leisure, the internet and popular culture: Communities and identities in a digital age. Basingstoke,UK: Palgrave.

Sprague, J. (2005). Feminist methodologies for critical researchers: Bridging differences. Walnut Creek, USA: Lanham.

Sumner, A., Waller, G., Killick, S., \& Elstein, M. (1993). Body image distortion in pregnancy: a pilot study of the effects of media images. Journal of Reproductive and Infant Psychology, 11(4), 203-208.

Tiidenberg, K. (2015). Odes to heteronormativity: Presentations of femininity in Russianspeaking pregnant women's Instagram accounts. International Journal of Communication, 9(13), 1746-1758.

Tiidenberg, K., \& Baym, N. K. (2017). Learn it, buy it, work it: Intensive pregnancy on Instagram. Social Media+ Society, 3(1), 2056305116685108.

Van Doorn, N., Wyatt, S., \& Van Zoonen, L. (2008). A body of text: Revisiting textual performances of gender and sexuality on the internet. Feminist Media Studies, 8(4), 357-374.

Weedon C. (1997). Feminist practice and poststructuralist theory. London,UK: Blackwell 
Wiles R. (1994). 'I’m not fat, I'm pregnant': The impact of pregnancy on fat women's body image. In S, Wilkinson \& C., Kitzinger (Eds). Women and health: Feminist perspectives (pp.33-48). London, UK: Taylor and Francis.

Willmott, A. (2013). Pregnant in heels: A critical analysis of the ideal, maternal body in celebrity magazines (Unpublished master’s thesis). Queen’s University, Canada. 